\title{
Ecosystem Health Education: \\ Teaching Leadership Through Team-Based Assignments
}

\author{
Elizabeth Sopdie \\ University of Minnesota \\ Tiffany Wolf \\ University of Minnesota \\ Scott Spicer \\ University of Minnesota \\ Shaun Kennedy \\ University of Minnesota \\ Kaylee Myhre Errecaborde \\ University of Minnesota \\ World Health Organization \\ Barrett Colombo \\ University of Minnesota \\ Cathy Jordan \\ University of Minnesota \\ Dominic Travis \\ University of Minnesota
}

The health and sustainability of humans, animals, and environments are interdependent. The relationship
between climate change, disease emergence, and food security on sustainability of ecosystem services is
embodied in the sustainable development goals (SDGs). A diverse workforce needs to be equipped with
leadership skills to function in a transdisciplinary, team-based environment. Ecosystem health (ESH)
provides a critical and innovative approach to solving these complex challenges and offers a toolbox to
actualize SDGs. This article outlines the development of a course detailing the process of framing a new
academic approach in ESH as a training pathway for undergraduate and graduate students.

Keywords: ecosystem health, team leadership, sustainable development goals, ecosystem health education 


\section{INTRODUCTION}

Grand challenges at the interface of humans, animals and environment are more complex and urgent than ever. In its most recent and comprehensive report, the United Nations Intergovernmental SciencePolicy Platform on Biodiversity and Ecosystem Services (IPBES) states, "The health of ecosystems on which we and all other species depend is deteriorating more rapidly than ever. We are eroding the very foundations of our economies, livelihoods, food security, health and quality of life worldwide" (IPBES, 2019). A major conclusion of this report is that all global stakeholders must shift resources toward development of approaches that support maintenance of these systems, optimizing between the sustainability of nature (with its ecosystem services) and the direct needs of growing global livestock and human populations.

The health and sustainability of humans, animals, and environments are not discrete, but interconnected and interdependent (Foley et al., 2011). The complex relationship between climate change, disease emergence, food and water security, gender, conflict, and poverty on the sustainability of ecosystem services that support human and animal health is well documented and embodied in the United Nations Sustainable Development Goals (SDGs) for peace and prosperity (Alcamo et al., 2003; Costello et al., 2009; Myers et al, 2009; Myers et al., 2013; Patz et al., 2014; Wilcox et al., 2019a; Wilcox et al., 2019b). The SDGs "recognize that ending poverty and other deprivations must go hand-in-hand with strategies that improve health and education, reduce inequality, and spur economic growth - all while tackling climate change and working to preserve our oceans and forests" ("Sustainable development goals: History," n.d.). For these issues, traditional, single-solution progress is insufficient. A strong workforce emerging from diverse disciplines - including food systems, agriculture, natural resources, and human sciences - will need to be sustainability ${ }^{1}$-savvy (Marshall \& Toffel, 2005; Wiek et al., 2011); prepared to function in a transdisciplinary, team-based environment; and equipped with the leadership skills to navigate complexity, balance diverse stakeholders' needs, and respond to unforeseen situations. The rapidly-evolving discipline of ecosystem health (ESH), grounded in community-focused transdisciplinary science and diverse ways of knowing, provides a critical approach to solving these problems and successfully achieving the SDGs. ESH optimizes human, animal, and environmental health priorities, merging theories and methods of ecological and health sciences and policy, thus balancing sustainable human and animal health with ecosystem management (Wilcox et al., 2004; Wilcox, 2008).

Several paradigms including 'One Health' (Zinstagg et al., 2011), planetary health (Stone et al., 2018; Whitmee et al., 2014), and ESH have been put forth as platforms to embrace such complexity. Many use these terms interchangeably, but there are disciplinary differences (Buse et al., 2018). Like the paradigms mentioned here, the 'discipline' of ESH (sometimes termed ecosystem approaches to health) is grounded in a system-based methodology and transdisciplinary, or inter-professional, science (Rapport, 1998, 1999). ESH recognizes "the inherent interdependence of the health of humans, animals and ecosystems and explores the perspectives, theories and methodologies emerging at the interface between ecological and health sciences" (Wilcox et al., 2004), and differs slightly from other collaborative theories in that ESH has an extensive record in peer-reviewed publications highlighting the approach and methodologies used (Rapport, 2003). Specific to ESH, this includes working with a diverse set of stakeholders, from local communities directly affected by loss or change in ecosystem services, to those involved in the value chains of these products (the network of producers and consumers), as well as those charged with land use and natural resources management and policy. In essence, ESH is complexity science aimed at identification and implementation of sustainable outcomes optimized among often disparate stakeholders under extreme conditions.

Philosophically, ESH is based on the belief that "health is improved by changing the way people interact with their environment, based upon research findings" (Charron, 2012). Primary ESH methods were designed to limit historical neocolonial or socially unjust research, compartmentalization of disciplines, and a lack of community participation in designing their own solutions (Forget, 1997). To implement ESH, one must embrace and implement a set of core principles: systems thinking, transdisciplinary research, participation (leading to awareness, collaboration, and progress by breaking down silos and barriers), 
sustainability, gender and social equity, and knowledge to action. The research paradigm then includes: participatory design (stakeholder inclusion and power analysis, collaborative visioning, integrative methods), knowledge development (systems or complexity science), systemization (adaptive interventions, solutions and policies), and intervention strategies (action plans that are tested and monitored) (Charron, 2012).

Despite the widely recognized need for ESH approaches in the workforce, there is mounting evidence of an emerging shortage of those trained in ESH sciences. A 2013 NIFA study indicates a 39\% shortage in new U.S. graduates with expertise in agriculture, food, renewable natural resources, or the environment to fill the expected 57,900 annual openings (Goecker et al., 2015); a gap that is only likely to grow given anticipated generational turnover and rural economics. To fill the post-baby boom workforce void, academia needs to respond to a new set of educational demands and workforce needs. This requires enhanced cross-disciplinary competency and greater reliance on effective and diverse teams. It is widely recognized that extension personnel and the agricultural workforce need next-generation professionals to have strong communication, leadership, and relationship skills to replace retiring workers (Cochran et al., 2012; Borr \& Young, 2010). New professionals require new education systems, which in turn require new kinds of teachers working within administrative platforms supportive of these goals.

The ESH paradigm is an innovative response to today's complex problems and offers a toolbox of methods that can be used to help each individual worker actualize their work in support of SDGs. Teaching these methods under the constrictions of a traditional education model also requires innovation (McCullagh et al., 2012; Stone et al., 2018). To this end, this article outlines the development of a course as a case study detailing the process of framing a new academic approach, which was first presented in 2020 at the annual Conference on Global Learning hosted by the Association of American Colleges and Universities (AAC\&U). This course represents a new innovative training pathway for undergraduate and graduate students at the University of Minnesota (UMN) focused on ESH, SDGs, and grounded in the interdisciplinarity of the UMN's Grand Challenges Curriculum (GCC).

\section{COURSE DEVELOPMENT}

In 2015, UMN launched the GCC in support of the University's strategic plan. The GCC "addresses important societal challenges through a solution-driven interdisciplinary approach to learning," and each course focuses on a specific 'wicked' societal issue while meeting common GCC goals of teaching students communication skills, problem definition, tolerance of ambiguity, collaboration, intercultural competence, personal agency, and systems thinking (GCC, 2021). GCC courses are team-taught by instructors in multiple disciplines to create inherent interdisciplinarity, and a centralized office supports and coordinates course promotion and enrollment. As of January 2021, there were over 30 GCC courses focused on societal issues such as climate change, global health, and human rights issues.

A team of interdisciplinary instructors, many but not all of whom are involved in writing this paper, developed an ESH course within the GCC, first delivered in 2018, titled, "Ecosystem Health: Leadership at the Intersection of Humans, Animals, and the Environment." The core team of instructors, with backgrounds in veterinary medicine, epidemiology, policy, education, and engineering, has led the course each spring since its inception. The course - cross-listed in the undergraduate and graduate course catalog - promotes interdisciplinary student enrollment and typically draws senior undergraduate students as well as graduate and professional students. Over the four-year history of the course, students have participated from a vast array of fields of study such as biology, biochemistry, applied economics, neuroscience, public health, architecture, animal science, global studies, computer science, music, mathematics, design, public affairs, development practice, nursing, veterinary medicine, conservation science, and the ever-popular "undecided" undergraduate major. The course also features numerous guest speakers and a close partnership with a media outreach librarian who supports student group projects. Each semester, the instruction team includes a teaching assistant, typically a graduate student whose dissertation research has an ESH focus, who not only facilitates course management but also contributes to course discussion, student mentorship, and the delivery of ESH case studies. 


\section{COURSE FORMAT}

This course uses an ESH approach to analyzing and solving complex problems and recognizes and embraces differences between disciplinary approaches. The course content is structured into three main phases within the process of ESH: 1) problem formulation, which includes systems thinking and stakeholder inclusion; 2) assessment of existing solutions and innovation, including indicators, measurements, and optimization; and 3) implementation and evaluation, which includes elements of design thinking, public policy, organizational management and leadership, monitoring and evaluation, and an analysis of unintended consequences (Figure 1). An introduction to the SDGs early in the semester ensures that learning is focused on global as well as local challenges.

\section{FIGURE 1 \\ PROCESS OF ESH ANALYSIS}

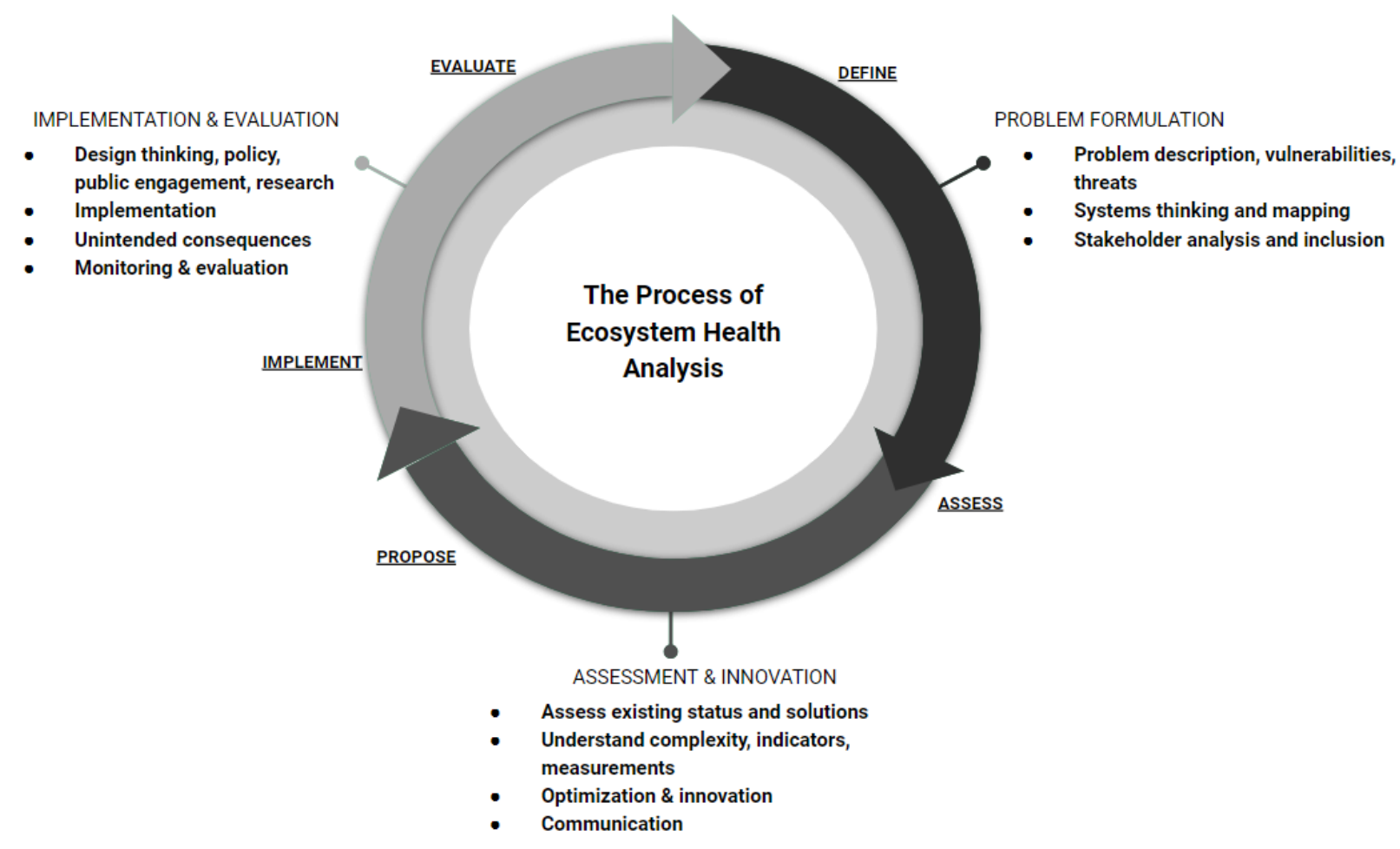

The course content is designed with a series of weekly modules (Table 1), each designed to build on the previous week's lesson and toward a final group project (Table 2). The grading is split between individual assignments or participation and group milestones that culminate in the final project. The teambased final project promotes shared leadership and skill development for working in teams. Each week before class, students complete readings, view videos and craft an online written reflection for discussion in response to a related prompt. The three-hour class period is broken down into three basic elements: a recap of online discussion or additional reflection followed by an intentionally brief lecture in the first hour to introduce new concepts; with the second hour focused on activity(s) and interactive case study(s) to practice applying the module's skill/theme; and time set aside for group project work in the third hour. As the semester proceeds, more time is dedicated to group project work and team deliverables. All assignments are scaffolded through the semester with the final element being the group project. The course content, including the case studies, team projects, and a graduate student cohort (outlined in greater detail below), is designed to promote interactive and competency-based learning. The final group project is the 'capstone' element of the course and requires students to present their problem definition, full analysis, and innovative 
solution in a ten-minute presentation, which has been, to date, in the form of a short film. In 2021, we further clarified project pathways, which represented different foci for the final film: policy, public engagement, or research (Figure 2).

TABLE 1

WEEKLY COURSE MODULES HIGHLIGHTING ESH CORE CONCEPTS

\begin{tabular}{|c|c|c|c|}
\hline Week & Module & $\begin{array}{c}\text { Individual Project } \\
\text { Milestones }\end{array}$ & $\begin{array}{l}\text { Group Project } \\
\text { Milestones }\end{array}$ \\
\hline 1 & $\begin{array}{c}\text { Introduction \& Ecosystem Health } \\
\text { Methods I }\end{array}$ & $\begin{array}{c}\text { "Finding a Fact," syllabus } \\
\text { review }\end{array}$ & \\
\hline 2 & Systems Thinking I & & $\begin{array}{c}\text { Team formation \& } \\
\text { contract }\end{array}$ \\
\hline 3 & Systems Thinking II & & Draft systems map \\
\hline 4 & $\begin{array}{c}\text { Soc.-Eco. Systems; Inclusive } \\
\text { Teams }\end{array}$ & $\begin{array}{l}\text { Draft problem summary } \\
\text { and systems map for peer } \\
\text { review }\end{array}$ & \\
\hline 5 & Stakeholders, Policy, \& Power & & \\
\hline 6 & Indicators & $\begin{array}{l}\text { Draft paper for peer } \\
\text { review (Modules 1-5) }\end{array}$ & $\begin{array}{c}\text { Draft list of current } \\
\text { solutions }\end{array}$ \\
\hline 7 & Communication & & $\begin{array}{c}\text { Milestone I: Case } \\
\text { abstract, conceptual } \\
\text { systems diagram, list of } \\
\text { current solutions }\end{array}$ \\
\hline 8 & Complexity \& Outcomes & Individual Paper Due & Final project selection \\
\hline 9 & $\begin{array}{c}\text { Resiliency \& Unintended } \\
\text { Consequences }\end{array}$ & & $\begin{array}{l}\text { Milestone II: Stakeholder } \\
\text { analysis and optimized } \\
\text { preferred end state }\end{array}$ \\
\hline 10 & $\begin{array}{l}\text { Monitoring \& Evaluation for } \\
\text { Collaborative Advantage }\end{array}$ & & \\
\hline 11 & Case Studies \& Team Project Work & & $\begin{array}{c}\text { Milestone III: New } \\
\text { solution, implementation, } \\
\text { unintended consequences }\end{array}$ \\
\hline 12 & Case Studies \& Team Project Work & & \\
\hline 13 & Case Studies \& Team Project Work & & Full Draft Due \\
\hline 14 & Case Studies \& Team Project Work & & \\
\hline 15 & Final Symposium & & \\
\hline
\end{tabular}


FIGURE 2

\section{ILLUSTRATION OF COURSE MILESTONE (MS) ASSIGNMENTS LEADING TO FINAL} PROJECT FOCUS OPTIONS

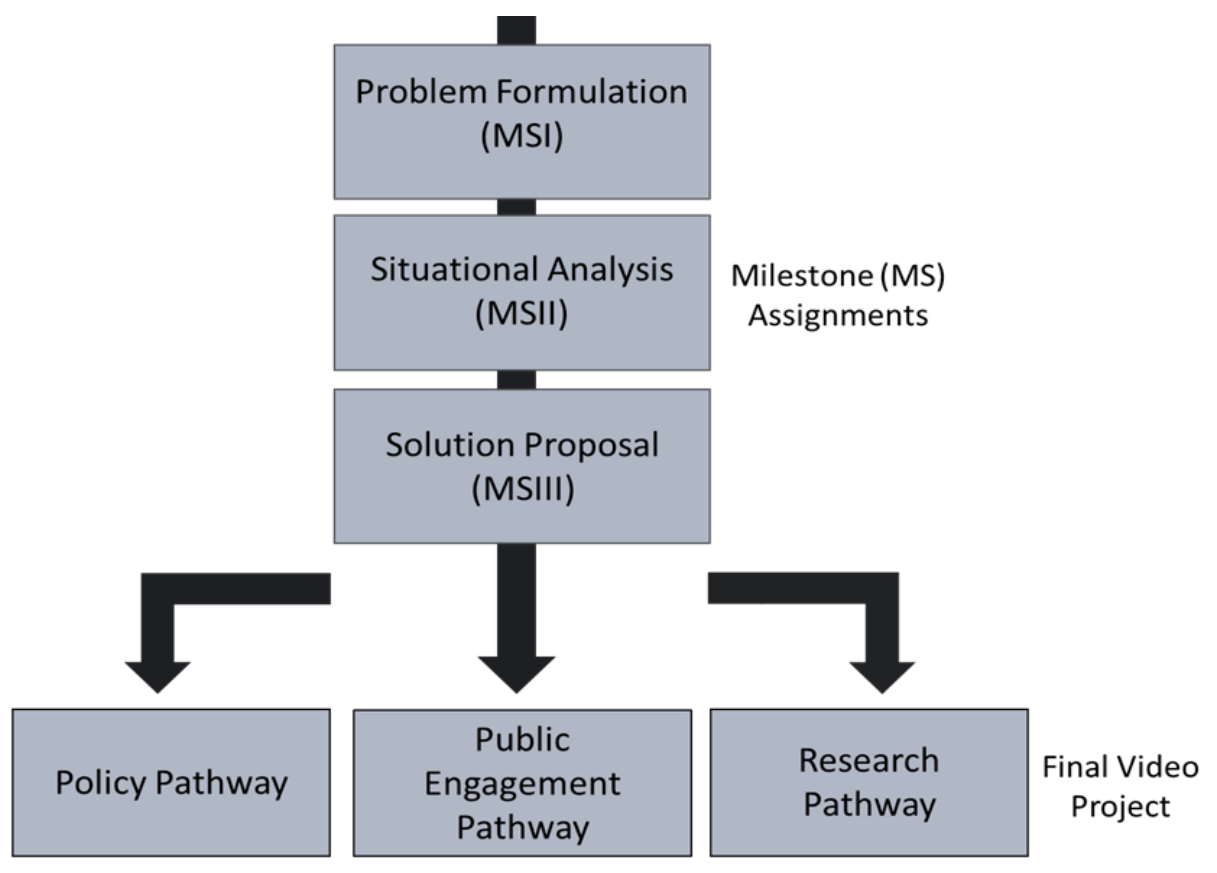

TABLE 2

STUDENT TEAM FINAL PROJECT TITLES, 2018-2020

\section{8}

- Environmentally Ethical and Efficient Production of Algae Biofuel

- The Impact of Sodium Chloride on Twin Cities Metro Area Ecosystems

- Gorse Invasion in Bogotá

- On a Path Towards Sustainable Diets Crickets as an Alternative to Unsustainable Protein Consumption

- Coalition Toward Stabilizing Cocoa, Theobroma cacao

- Cold Chain Analysis of the PPR Vaccine: A case study in Turkana, Kenya

$\underline{2019}$

- Ecosystem of Lake Victoria

- The Grand Challenge of Fast Fashion

- Moose Conservation Center of Minnesota

- Invasive Bigheaded Carp on the Mississippi River

2020

- Wildfire and Water

- Eco-boost My Lunch: Revamping Minneapolis' District Lunches

- Plastic Use Pollution

- Wild Bison: Conservation of the Great American West

- Malaria Mortality Prevention in the Eastern Africa Highlands 


\section{Case Studies}

Case-based teaching is a long-standing pedagogical approach that blends theory and practice and engages students in real-world examples. It promotes interaction, knowledge building, and collaboration, and requires analyzing complex problems that most often may not have a single right answer (Thistlethwaite et al., 2012). Case-based learning (CBL) can be classified as a guided learning approach, in which students can grapple with a problem while working with a facilitator who keeps the inquiry focused on the desired learning objectives (Srinivasan et al., 2007). Tawfik and Kolodner (2016) argued that CBL "gives failure and iterative refinement central roles in promoting learning and facilitation," which leads to inquiry and more developed reasoning processes. This approach also allows students to apply concepts to authentic issues within an industry or discipline. In ESH, several evaluations of 15 years of training in Canada recommended a structured case-based approach to quantitative and social science skill set integration (Ole Nielsen, 2012; Stephens, 2009), ideally augmented by problem-based field practica (Ribble et al., 1997), the latter of which is not, to date, reflected in this course.

CBL is well-suited to ESH problems and to the structure of this class. We use CBL to allow students to practice hands-on application of the weekly module concepts and problem-solve both individually and in their project teams. Students must grapple with multiple pathways and processes that could lead to solutions (or not) of ESH problems. CBL also lends itself readily to the scaffolding of our assignments and weekly modules. In early iterations of this class, we used a different ESH case each week to illustrate core concepts but developed over the years to instead use one primary case that is carried through the semester with select additional case studies as warranted. In 2019 we highlighted the complex challenge of evergrowing amounts of plastic in the ocean; in 2020 and 2021, we utilized COVID-19. In particular, the casestudy of COVID-19 allowed students to apply and analyze course concepts on a real-time, emerging global pandemic that involved a complex interface between animals, humans, and the environment, as well as a host of cultural, economic, and social factors.

\section{Project Teams and Leadership}

This course embraces the tenants of integrative leadership, which brings diverse groups and organizations together, often across sector boundaries, to address public problems for the common good (Crosby \& Bryson, 2010). Often aptly called shared leadership, this practice emphasizes "leaderly" actions from collaborators who may not hold formal positions of power in situations where there is likely no one 'winner' of a problem. Shared and integrative leadership can more often lead to lasting social change in situations where complex challenges necessitate collaboration across multiple different organizations or individuals, referred to as collective impact (Quick, 2017).

To promote shared leadership across students from different disciplines, diverse backgrounds, and various stages of their academic careers, team-building exercises are used frequently in the beginning of the semester to promote relationship building. Through these exercises, as well as weekly reflections, students are encouraged to gain a grounded understanding of how they each work individually as well as how they work with others on a team. We also introduce theories about teamwork and team functioning, such as Tuckman's (1965) "forming, storming, norming, performing," model, and concrete strategies for working across differences in team settings (Ernst \& Yip, 2009; Gratton et al., 2007).

The largest element of this course that promotes team building and leadership is the final group project. Early in the semester, students are placed by instructors on interdisciplinary project teams consisting of four to six students, depending on the class size. Each team contains at least one graduate student, who acts as a project leader through the semester. The graduate student cohort and leadership is described in greater detail below.

On the first day that teams are formed, they are provided with a template to create a group contract that establishes how they intend to communicate, share the workload, and create a respectful and productive team environment. From there, project teams work together on physical or virtual whiteboards throughout each class period whenever there is opportunity for reflection or practice as part of the active teaching and learning process. As the semester progresses, there is a greater allocation of class time toward group work, giving students ample in-class time to work in teams while course instructors move between teams to 
answer questions, offer feedback and promote inquiry. Instructors focus on offering formative feedback for project teams to analyze and adopt, adapt or reject. We have found that having multiple instructors from disparate backgrounds and expertise offering formative feedback provides students an opportunity to practice reconciling multiple and sometimes conflicting perspectives to strive for optimization. At the end of the semester, in addition to participation grades assigned by instructors, project teams use a peer review form to grade and offer constructive feedback on work performance and collaboration to their project teammates.

\section{Graduate Student Leadership, Communication \& Project Management}

The course was designed for the integration of undergraduate and graduate students, and early in its development was the challenge of creating a separate rubric for higher level assessment of graduate student performance. At inception, we used a traditional approach to assessment where graduate students were expected to demonstrate a higher level of synthesis of course concepts and literature through their individual writing assignments and development of ESH solutions (Anderson \& Krathwohl, 2001; Betts, 2008). We also had graduate students positioned as project team leaders when it came to the larger team-based semester project. The intent was to reflect the 'real-world' workplace, with teams composed of people with different experience levels and/or backgrounds, organized by a team leader, all working toward a common goal (Ernst \& Yip 2009, Gratton et al., 2007). This approach required students to actively engage in the skills that formed the basis for project success - shared leadership, collaboration, setting clear expectations and goals, and multidisciplinarity (Bennet \& Galdin, 2012, Errecaborde et al., 2019) - while also developing ESH skills directly related to project development - systems mapping, stakeholder assessment, and science communication, among others (Charron, 2012).

This initial hierarchical course design was determined to be challenging, if not problematic, early on. The problem was, in part, due to students' inexperience in team-based coursework where success was very much dependent on collaboration and not individual knowledge and learning. Graduate students naturally had different expectations for quality in their teams' products, and in many cases struggled to identify optimal ways of working with undergraduates with generally less experience and practice in writing, goal setting, and time management. Simultaneously, undergraduate students were relying heavily on graduate students for decision-making and polishing of course assignments. This combination required early and regular instructor intervention to ensure equity of the workload across team members. Where graduate students were inadvertently burdened with a greater workload because of their higher level of experience and development of the afore-mentioned skills, they generally did not yet have the skills or feel enabled to manage a team under a shared leadership model (Jackson, 2000; Kocolowski, 2010).

The solution to this challenge was an opportunity to enhance training in shared leadership, as well as other critical skills needed in team science (e.g., conflict resolution, communication). While maintaining the hierarchical and multidisciplinary structure of student teams, we also created a graduate student learning cohort. The cohort was organized such that, as student teams progressed through the semester on their respective projects, the graduate students would meet separately and intermittently through the semester as team leaders, along with instructors, to discuss progress on projects and challenges they were experiencing. This new space for graduate students opened up discussions about communication styles and feedback, workload management and empowering team leadership, conflict resolution, and strategies to ensure inclusivity of all team members. The nature of these cohort meetings was unstructured and informal, with open dialogue that promoted peer teaching and learning. In addition to the implementation of graduate student learning cohorts, we continued to emphasize support for the shared leadership model to the entire class with messages of accountability, partnership, equity, and ownership as a basis for successful teamwork (Jackson, 2000).

In responding to the graduate students' need for additional support and guidance in team management and working under a shared leadership model, a new pathway toward competency-based learning has emerged. It affords the opportunity to move further away from the traditional approach to assessment based on higher level of performance by graduate students on individual assignments (Anderson \& Krathwohl, 2001; Betts, 2008). Under a model of competency-based learning, a new set of formal evaluations for 
graduate students is emerging, which includes a series of self-assessments by graduate students at the beginning and end of the course, as well as a final instructor-based evaluation. In combination with the established graduate student cohort meetings, these structured evaluations provide a more formal assessment of their development in shared leadership, communication, project management, and other skills, while also giving them experience with the kind of evaluation and feedback they will receive in the workplace.

\section{Final Team Project and Film Festival}

In 2018, the first year the course was offered, the final team project was a written "grand challenge" grant proposal. Student and instructor feedback suggested that we needed to re-design the final team project assignment to offer greater creative expression and student engagement and that we could create a final project format that also served as a communication tool across a wide range of audiences. In 2019, we developed a partnership with a media outreach librarian (Scott Spicer) who functions as head of the University of Minnesota Libraries' Media Services program. Spicer was brought in to consult with the instructional team on developing and coordinating support for a video assignment that would tell the story of the team's grand challenge.

This video project presented some early challenges as it essentially incorporated two complex course concepts into one assignment. The first part required that students research and communicate the background, systems map relationships, and key stakeholders of an ESH grand challenge. This portion was a documentary-style video investigation designed to be more informational and balanced. The second half of the video was a solutions-modeling approach that required students to propose a creative and novel solution to an ESH challenge. Beyond communicating an innovative solution, the students also needed to consider their proposed solutions' unintended consequences. This additional requirement is notable because solutions-modeling videos are typically expected to simply propose a creative "blue sky" solution. Adding the reflective unintended consequences expectation encouraged critical thinking by forcing students to further wrestle with the challenges of these issues.

Given the assignment's complexity, we carefully scaffolded media creation considerations with the ESH concepts the students learned throughout the semester. Spicer visited the classroom early in the semester to provide an overview of media creation support resources (e.g., library-based equipment, software, computing, on-demand support). He offered tips for the media creation process, including storyboarding, scripting, composition, copyright, citation/attribution, and sharing permissions. This initial visit aimed to encourage groups to start thinking intentionally about what concepts and topics they wanted to communicate in their videos with ideas on how best to represent these ideas using multimedia.

A well-crafted, course-integrated, and student-created media assignment is ideal for deeply engaging students with the subject matter (Lee, 2014; Moreau et al. 2018; Walters et al., 2018). The scaffolded creation of students' videos required a deep dive into a case study and ESH concepts. For example, an integral course concept is the creation of a systems map that visually displays the complexity of an ESH grand challenge. As students thought about the overall structure of their ESH challenge, they were also invited to start thinking about which aspect of the map would become the focus of the video project. To illustrate, one video on Fast Fashion described the harmful human rights and environmental impacts of consumer preferences for cheap, fashionable clothing ("Video investigation + solutions video," 2019). Displaying an illustrated systems map, the group discussed the complex system of the global supply chain from manufacturer to retailer in the video. In the second part of the video, in response to this challenge, students proposed a solution that included taxes on retailers and incentives for social media influencers to offset these negative costs. In creating this video, the students applied and reinforced their understanding of the concepts they had learned throughout the semester through storytelling and multimedia.

In addition to subject knowledge acquisition, several secondary benefits are also realized from this team media project. For example, given that the GCC course includes both undergraduate- and graduate-level students across a broad range of disciplines, one of the learning objectives is to engage students with other students outside of their academic and experiential comfort zones. This includes team leadership for the graduate students and peer leadership and collaboration for all students. Managing the logistics and 
interpersonal dynamics of this group assignment to completion is useful for project management in other contexts. The students also develop technical and compositional multimedia skill sets that support media literacy and are transferable to the workplace. Finally, through this video creation, the students have an opportunity to hone their science communication skills, leveraging modern tools, formats, and communication strategies to communicate the importance of these critical challenges.

Since 2019, each student group screens their video as part of a film festival at the end of the semester. This event includes a live presentation introducing each topic along with a question and answer component to conclude. The live presentation format presses students to demonstrate their mastery and creative thinking about these issues, spurred by a rich discussion with the audience that includes stakeholders and other visitors outside of the course.

\section{Reflections on the Transition to the Virtual Environment}

In the spring of 2020, we found ourselves living in the very challenges that ESH aims to address. In March, classes previously held in person in an active-learning classroom (circular tables with cables for student teams to project their slides, whiteboards, multiple presentation screens) were transitioned to virtual learning and we held the latter two-thirds of the course online via Zoom. We decided to continue holding the class synchronously at the assigned time but cut the "class" period down significantly to avoid a full three hours on Zoom. This required us to record some lectures delivered as pre-class work, which also served to make our online delivery much more engaging through features on Zoom, like chat or a virtual whiteboard, or collaborative applications like Google slides or Jamboard. As previously mentioned, we also focused on COVID-19 as a case study that was carried throughout the semester, which offered the double benefit of using a real-world, impactful issue to analyze with ESH methods as well as granting the opportunity to discuss and make sense of the events unfolding around us.

Expectations for the final video team project also required modification due to the COVID-19 pandemic outbreak and transition to virtual learning. Students began working individually from home and collaborating virtually over Zoom. We decided to lower the technical expectations of the project and emphasize still imagery (photos), text, and voice-over instead of video clips that required more advanced technical skills or software only available on campus. Spicer, Wolf, and Sopdie provided virtual presentations on visual literacy (image selection) and digital storytelling to help students reconceptualize their projects, and Spicer continued to offer virtual support for student groups outside of class. The final film festival was held via Zoom at the end of the semester instead of in person, which offered the benefit of being able to invite and include more guests, including University faculty or staff as well as students' family members. In the spring of 2021, we offered this course virtually again, using lessons learned from the sudden transition to virtual learning to offer active, dynamic, and engaging Zoom sessions. The format and pacing of this course lends itself readily to virtual delivery, and we continue to be impressed with the level of engagement from students even in a virtual learning environment.

\section{FUTURE ESH INITIATIVES}

Training in ESH must be responsive to both employer- and student-identified needs and be coordinated with student educational requirements. To improve educational quality and realize student impact, we need transparent undergraduate and graduate student pathways that integrate curricular and co-curricular components emphasizing ESH and experiential learning, that are tailored for students in various disciplines, and that are developed and implemented among units offering sustainability education and leadership development. Furthermore, the sustainability challenges of today not only require the coordinated efforts of diverse disciplines and sectors, but diversity of thought, experience, and background (Gompers, 2018). As our country's demographics shift, we must acknowledge that the workforce will suffer from a deficit of diverse perspectives unless we recruit and retain first generation students, students of color and Native American students, and other underrepresented and under-resourced students into ESH fields and support their educational success and career development. 
These needs, at least at the undergraduate level to start, are being addressed through "Meeting Workforce Needs of the Future: Educational Pathways to Ecosystem Health Preparedness," funded by the USDA National Institute of Food and Agriculture. In this training grant we are conducting a multi-phased approach to developing ESH competencies grounded in assessed workforce needs and trends and mapping them to existing courses as well as creating new courses to create an ESH pathway in the UMN's alreadyestablished Sustainability Studies Minor. "Ecosystem Health: Leadership at the Intersection of Humans, Animals, and the Environment" - the course presented here - will serve as an important core course for the ESH pathway. Part of this training grant will also involve the creation of a faculty community of practice oriented to SDGs and equipped with tools of the ESH approach to further support course development for students as well as teaching efforts across disciplines. Another critical element of this work involves recruiting and retaining previously underrepresented student groups into this ESH pathway and continuing to update curricular content with an eye toward antiracism, social justice, and indigenous ways of knowing.

Student evaluations of this course over time have been both positive and constructive, helping us finetune some of the complexities of the assignment scaffolding and most notably refine the graduate student cohort. We have found that student teams are most engaged when the material includes the intersection of environmental/biodiversity, sustainability, food and water security, climate variability, and health (toxicology, nutrition, infectious diseases). In addition, feedback suggests that students and instructors value the inclusion of tools from multiple disciplines such as stakeholder analysis, design thinking, cultural anthropology, comparative systems mapping, validation of biological indicators, and science communication for policy-making and general audiences. These findings mirror those in the relatively small published literature evaluating ESH approaches.

This course has spurred several other ESH-related initiatives. In the spring of 2021, a subset of this instructor team developed a new freshman seminar course that can be offered as an introductory class. We have begun to adapt course content into discrete online modules and presentations for other audiences, and an experiential companion course is also planned. We have also shared iterations of the course development process at the 2020 AAC\&U conference, as mentioned earlier, and shared our development process during a satellite workshop at the 2021 Planetary Health Alliance conference.

\section{CONCLUSION}

The ESH process is an innovative response to today's complex problems that affect humans, animals, and the environment and a toolbox of methods that can help workers to conceptualize their daily work, no matter the sector or discipline, in support of the SDGs. The current COVID-19 pandemic has further highlighted the urgency of training future scholars and practitioners to solve complex challenges at this interface. ESH challenges require graduates to be equipped with enhanced cross-disciplinary and teamscience competencies, with strong communication and leadership skills. As a foundational element of our USDA NIFA-funded workforce development grant, our course contributes to an emerging model for addressing the need for a more diverse workforce and the predicted shortage of new U.S. graduates with expertise in agriculture, food, renewable natural resources, and the environment to fill an expected 57,900 annual openings noted above (Goecker et al., 2015). Over the course of this class's history, we have framed a new approach to teaching and learning by developing and refining a training pathway for undergraduate and graduate students. Grounded in interdisciplinarity and oriented to SDGs and current grand challenges

the world faces, this course offers students the opportunity to learn, practice, and apply ESH skills in individual and team settings for a solution-driven approach to solving the world's most complex challenges.

\section{ACKNOWLEDGEMENTS}

The authors would like to acknowledge the following for their contributions to and support of this course development since 2018: Mateo Convertino, Yang Lui, Jessica Deere, Katie Worsley-Tonks, Marissa Milstein, Margaret McEachran, Chris Schaffer, Leslie Schiff, Courtney Lang, and Katie Russell. 


\section{ENDNOTE}

1. By "sustainability" we offer a chronological interpretation that can be summarized as "meets the needs of the present without compromising the well-being of future generations." (Report of the Brundtland Commission, Our Common Future, 1987).

\section{REFERENCES}

About. (n.d.). Grand Challenges Curriculum [GCC]. Retrieved January 15, 2021, from https://gcc.umn.edu/about

Alcamo, J., Ash, N., Butler, C., Callicott, J., Capistrano, D., Carpenter, S., ... Zurek, M. (2003). Ecosystems and human well-being: A framework for assessment. Washington, D.C.: Island Press.

Anderson, L.W., \& Krathwohl, D. (2001). A taxonomy for learning, teaching, and assessing: A revision of Bloom's taxonomy of educational objectives (complete edition). New York: Addison Wesley Longman.

Bennett L.M., \& Gadlin, H. (2012). Collaboration and team science: From theory to practice. Journal of Investigative Medicine, 60(5),768-75. doi: 10.2310/JIM.0b013e318250871d

Betts, S. (2008). Teaching and assessing basic concepts to advanced applications: Using Bloom's taxonomy to inform graduate course design. Academy of Educational Leadership Journal, 12(3).

Borr, M.L., \& Young, R.B. (2010). Retirement and attrition trends of extension professionals in North Dakota. Journal of Extension, 48(1).

Buse, C.G., Oestreicher, J.S., Ellis, N.R., Patrick, R., Brisbois, B., Jenkins, A., .. Parkes, M. (2018). Public health guide to field developments linking ecosystems, environments and health in the anthropocene. Journal of Epidemiology and Community Health, 72, 420-425.

Charron, D.F. (2012). Ecohealth research in practice. In D. Charron (Ed.), Ecohealth research in practice. Insight and innovation in international development (Vol 1). Springer, New York, NY.

Cochran, G.R., Ferrari, T.M., \& Chen, C.Y.T. (2012). Trends affecting Ohio State University Extension in the 21st century and the implications for human capital. Journal of Agricultural Education, 53(2), 43-57.

Costello, A., Abbas, M., Allen, A., Ball, S., Bell, S., Bellamy, R., . . Patterson, C. (2009). Managing the health effects of climate change. The Lancet, 373(9676), 1693-1733. https://doi.org/10.1016/S0140-6736(09)60935-1

Crosby, B., \& Bryson, J. (2019) Designing and implementing cross-sector collaborations: Needed and challenging. Public Administration Review, 75(5). https://doi.org/10.1111/puar.12432

Ernst, C., \& Yip, J. (2009). Boundary spanning leadership: Tactics to bridge social identity groups in organizations. In T. Pittinsky (Ed.), Crossing the divide: Intergroup leadership in a world of difference. Boston, MA: Harvard Business School Press.

Errecaborde, K.M., Rist, C., Travis, D.A., Ragan, V., Potter, T., Pekol, A., ... Dutcher, T. (2019). Evaluating One Health: The role of team science in multisectoral collaboration. Revue Scientifique et Technique, 38(1), 279-289.

Foley, J., Ramankutty, N., Brauman, K., Cassidy, E., Gerber, J., Johnston, M., ... Zaks, D. (2011). Solutions for a cultivated planet. Nature, 478(7369), 337-42. doi:10.1038/nature10452

Forget, G. (1997). From environmental health to health and the environment: Research that focuses on people. In G.S. Shahi, B.S. Levy, A. Binger, T. Kjellström, \& R. Lawrence (Eds.), International perspectives on environment, development and health: Towards a sustainable world. Springer, New York, NY, USA.

Goecker, A.D., Smith, E., Fernandez, J.M., Ali, R., \& Theller, R. (2015). Employment opportunities for college graduates in food, agriculture, renewable natural resources, and the environment: United States, 2015-2020. Retrieved from https://www.purdue.edu/usda/employment/wpcontent/uploads/2015/04/2-Page-USDA-Employ.pdf? 
Gompers, P., \& Kovali, S. (2018, July-August). The other diversity dividend. Harvard Business Review. Retrieved from https://hbr.org/2018/07/the-other-diversity-dividend

Gratton, L., Voigt, A., \& Erickson, T. (2007). Bridging faultlines in diverse teams. MIT Sloan Management Review.

IPBES. (2019). Summary for policymakers of the global assessment report on biodiversity and ecosystem services. In S. Díaz, J. Settele, E.S. Brondízio, H.T. Ngo, M. Guèze, J. Agard, . . . C.N. Zayas (Eds.), (Unedited advance version). Retrieved from https://www.ipbes.net/news/ipbes-globalassessment-summary-policymakers-pdf

Jackson, S. (2000). A qualitative evaluation of shared leadership barriers, drivers and recommendations. Journal of Management in Medicine, 14(3/4), 166-178. https://doi.org/10.1108/02689230010359174

Kocolowski, M.D. (2010). Shared leadership: Is it time for a change? Emerging Leadership Journeys, $3(1), 22-32$.

Lee, L. (2014). Digital news stories: Building language learners' content knowledge and speaking skills. Foreign Language Annals, 47, 338-356. https://doi.org/10.1111/flan.12084

Marshall, J.D., \& Toffel, M. (2005). Framing the elusive concept of sustainability: A sustainability hierarchy. Environmental Science \& Technology, 39(3), 673-682.

McCullagh, S., Hunter, B., Houle, K., Massey, C., Waltner-Toews, D., Lemire, M., ... Morrison, K. (Eds). (2012). Ecosystem approaches to health teaching manual: Canadian community of practice in ecosystem approaches to health. Retrieved from www.copeh-canada.org

Moreau, K.A., Eady, K., Sikora, L., \& Horsley, T. (2018). Digital storytelling in health professions education: A systematic review. BMC Medical Education, 18(1), 208. https://doi.org/10.1186/s12909-018-1320-1

Myers, S.S., \& Patz, J.A. (2009). Emerging threats to human health from global environmental change. Annual Review of Environment and Resources, 34, 223-52. doi:10.1146/annurev.environ.033108.102650.

Myers, S.S., Gaffikin, L., Golden, C.D., Ostfeld, R., Redford, K., Ricketts, T., ... Osofsky, S. (2013). Human health impacts of ecosystem alteration. Proceedings of the National Academy of Sciences of the United States of America, 110(47), 18753-60. doi:10.1073/pnas.1218656110

Ole Nielsen, N., Waltner-Toews, D., Nishi, J.S., \& Hunter, D.B. (2012). Whither ecosystem health and ecological medicine in veterinary medicine and education. Canadian Veterinary Journal, 53, 747-753.

Patz, J.A., Frumkin, H., Holloway, T., Vimont, D., \& Haines, A. (2014). Climate change challenges and opportunities for global health. JAMA. doi:10.1001/jama.2014.13186

Quick, K. (2017). Locating and building collective leadership and impact. Leadership, 13(4), 445-471.

Rapport, D.J. Costanza, R., \& McMichael, A.J. (1998). Assessing ecosystem health. Trends in Ecology \& Evolution, 13(10), 397-402.

Rapport, D.J., Bohm, G., Buchingham, D., Cairns, J., Costanza, R., Karr, J.R., ... Whitford, W.G. (1999). Ecosystem health: The concept, the ISEH, and the important task ahead. Ecosystem Health, 5, 82-90.

Rapport, J., Lasley, W.L., Rolston, D.E., Nielson, N.O., Qualset, C.O., \& Damania, A.B. (Eds). (2003). Managing for healthy ecosystems. Boca Raton, London, New York, Washington, D.C.: Lewis Publishers.

Report of the Brundtland Commission. (1987). Our common future. United Kingdom: Oxford University Press.

Ribble, C., Hunter, B., Lariviere, N., Belanger, D., Wobeser, G., Daoust, P.Y., ... Nielsen, O. (1997). Ecosystem health as a clinical rotation for senior students in Canadian veterinary schools. Canadian Veterinary Journal, 38, 485-490.

Spicer, S. (2019). Video Investigation + Solutions Video. Student Produced Sustainability Project Gallery. Retrieved March 5, 2021, from https://z.umn.edu/sustainabilityinvestigationsolutionsvideo 
Srinivasan, M., Wilkes, M., \& Stevenson, F. (2007). Comparing Problem-Based Learning with CaseBased Learning: Effects of a Major Curricular Shift at Two Institutions. Academic Medicine, 82(1), 74-82.

Stephen, C. (2009). The challenge of integrating ecosystem health throughout a veterinary curriculum. Journal of Veterinary Medical Education, 36(1), 145-151.

Stone, S.B., Myers, S.S., Golden, C.D., \& the Planetary Health Education Brainstorm Group. (2018). Cross-Cutting Principles for Planetary Health Education. Lancet Planetary Health, 2, 192193.

Tawfik, A.A., Kolodner, J.L., Tawfik, A.A., Illinois, N., Kolodner, J.L., \& Concord, T. (2016). Systematizing scaffolding for problem-based learning: A view from case-based reasoning. The Interdisciplinary Journal of Problem-based Learning, 10(1), 5-6.

Thistlethwaite, J.E., Davies, D., Ekeocha, S., Kidd, J.M., MacDougall, C., Matthews, P., . . Clay, D. (2012). The effectiveness of case-based learning in health professional education. Medical Teacher, 34(6), 421-44.

Tuckman, B.W. (1965). Developmental sequence in small groups. Psychological Bulletin, 63(6), 384-399.

United Nations, Sustainable Development. (n.d.). Sustainable development goals: History. Retrieved March 5, 2021, from https://sdgs.un.org/goals

Walters, L.M., Green, M.R., Goldsby, D., \& Parker, D. (2018). Digital storytelling as a problem-solving strategy in mathematics teacher education: How making a math engages and excites 21 st century students. International Journal of Technology in Education and Science, 2(1), 1-16.

Whitmee, S., Haines, A., Beyrer, C., Boltz, F., Capon, A., Ferreira de Souza Dias, B., . . Yach, D. (2015). Safeguarding human health in the anthropocene epoch: Report of The Rockefeller Foundation-Lancet Commission on Planetary Health. Lancet, 6736(15), 1973-2028. doi:10.1016/S0140-6736(15)60901-1

Wiek, A., Withycombe, L., \& Redman, C.L. (2011). Key competencies in sustainability: A reference framework for academic program development. Sustainability Science, (6), 203-2018.

Wilcox B., Alonso, A., De Paula, N., Boripat, S., \& Echaubard, P. (2019a). Operationalizing One Health employing social-ecological systems theory: Lessons from the greater Mekong sub-region. Frontiers in Public Health, 7(85). 10.3389/fpubh.2019.00085

Wilcox, B. (2008). Transdisciplinarity in ecohealth: Status and future prospects. EcoHealth, 5, 1-3. DOI: 10.1007/s10393-008-0161-5

Wilcox, B.A., Aguirre, A.A., Daszak, P., Horwitz, P., Martens, P., Parkes, M., . . Waltner-Toews, D. (2004). EcoHealth: A transdisciplinary imperative for a sustainable future. EcoHealth, 1(1), 3-5. doi:10.1007/s10393-004-0014-9

Wilcox, B.A., Echaubard, P., de Garine-Wichatitsky, M., \& Ramirez, B. (2019b). Vector-borne disease and climate change adaptation in African dryland social-ecological systems. Infectious Disease \& Poverty, 8(36). https://doi.org/10.1186/s40249-019-0539-3

Zinsstag, J., Schelling, E., Waltner-Toews, D., \& Tanner, M. (2011). From 'one medicine' to 'one health' and systemic approaches to health and well-being. Preventive Veterinary Medicine, 101(3), 14856. doi:10.1016/j.prevetmed.2010.07.003 